\title{
Tense IN AdJunCts Part 1: Relative Clauses
}

\begin{abstract}
Part 1 of Tense in Adjuncts presents a compositional analysis of tense in relative clauses (RCs). The languages under investigation are English, Russian and Japanese. We introduce the syntax and semantics of tense and the theory of feature transmission under variable binding, which mediates between syntax/semantics and morphology. In sequence of tense (SOT) languages such as English, the morphology of the tense in a RC will be licensed by a non-local tense if the RC is embedded under will. In other constructions, the RC tense is licensed by a local tense. In non-SOT languages, the tense in the RC is also determined by a local tense. The paper says which factors are responsible for the tense distribution in the different languages under consideration.
\end{abstract}

\section{INTRODUCTION}

Several semantic puzzles concerning tense in adjuncts were discovered in early works by Anscombe, Geis, and Heinämäki in the 1960s and 70s. In the 1980s, Stump (temporal adverbial clauses), and later Ogihara (relative clauses), drew attention to some interesting mismatches between tense interpretation and morphology in English, patterns reminiscent of sequence of tense (SOT) phenomena from complement tense, i.e., morphological tense agreement between the matrix and subordinate tense. Ogihara contrasted the English data with the non-SOT language Japanese. Kusumoto, and more recently Grønn and von Stechow, included Russian data into the analysis, another non-SOT-language.

In the two parts of this survey article, we present the state of the art and try to put all the pieces together in a suitable framework, which is explained in Part 1 of the paper. The emerging analysis of tense in adjuncts owes much to the insights of Ogihara, Kratzer and Kusumoto (relative clauses) - Part 1 of the current paper; Beaver and Condoravdi (before/after-clauses) and Arregui and Kusumoto (when-clauses) - Part 2 of our paper. ${ }^{1}$

\section{Tense Distribution in Relative Clauses}

The languages we will study exhibit the following distribution of tense in relative clauses (RCs).

$$
\text { English (Ogihara, 1996, Ogihara, 1989) }
$$

\footnotetext{
${ }^{1}$ We wish to thank the anonymous reviewers of Language and Linguistics Compass whose comments have greatly improved the final version of the two Parts of this paper.
} 
a. John met a man who was crying in sorrow.

b. John met a man who is crying in sorrow.

c. John will buy a fish that is alive. (expected: will be)

d. John will meet a man who lost his money. $\quad$ (expected: will have lost)

In a Past under Past configuration, the subordinate tense denotes a time somewhere before the speech time. In a Present under Past configuration (Pres $\backslash$ Past), Pres is deictic. The unexpected denotation is Pres|will: here Pres denotes a future time. Similarly, Past $\mid w i l l$ denotes a time before the time introduced by will but possibly after the speech time.

Yesterday John said he would answer every mail that was on his computer next week. (expected: will be or would be)

The deeply embedded "was" in (2) is not interpreted before the speech time. Similar data as in (1)/(2) have been given in (Abusch, 1994).

Russian (Kondrashova, 1992)

a. Masha videla ${ }^{\text {past,ipv }}$ cheloveka, kotoryj plachet ${ }^{\text {pres,ipv }}$. (deictic and independent) Masha see ${ }^{\text {past,ipv }}$ man who cry ${ }^{\text {pres,ipv }}$.

b. Masha videla ${ }^{\text {past,ipv }}$ cheloveka, kotoryj plakal ${ }^{\text {pres,ipv }}$. (deictic and independent) Masha see ${ }^{\text {past,ipv }}$ man who cry ${ }^{\text {past,ipv }}$.

The generally accepted view is that the tense in Russian RCs is deictic and therefore independent from the matrix tense. (Grønn and von Stechow, 2011) observed, however, that Future \Past can be shifted:

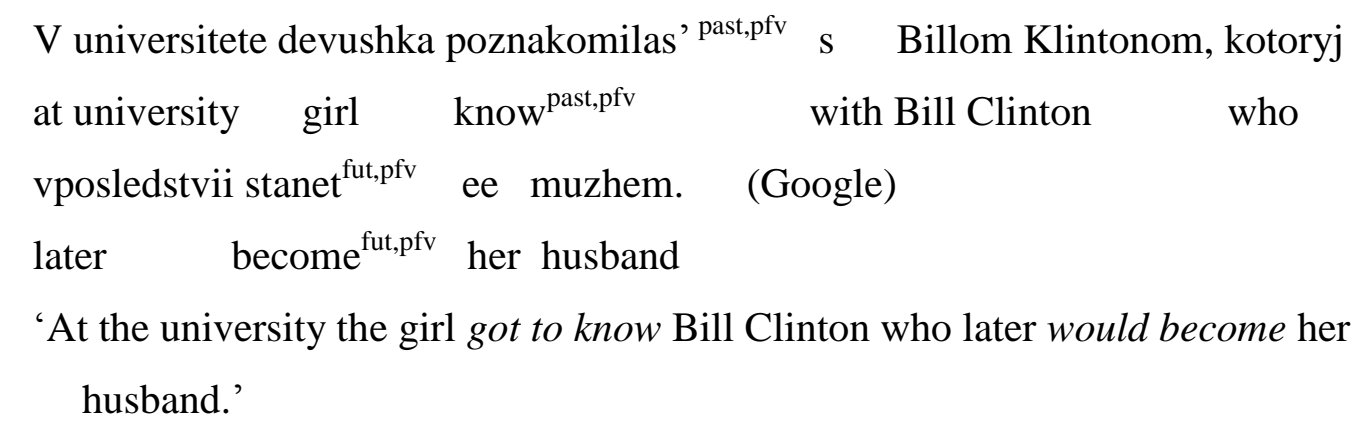

Japanese PastlPast configurations are like in Russian, i.e. the embedded Past is deictic. An embedded Pres, however, is either deictic or shifted; it can be shifted to a simultaneous past time or to a relative future time.

(5) Japanese Pres\Past (Ogihara, 1996), p. 154 
a. Taro-wa [nai-te ${ }^{\text {prog }}$ i-ru ${ }^{\text {pres }}$ otoko]-o mi-ta ${ }^{\text {past }}$

Taro-Top [cry ${ }^{\text {prog }}$ be $^{\text {pres }}$ man] see $e^{\text {past }}$

'Taro saw a man who was crying (at the time of the meeting)'

'Taro saw a man who is crying (now)'

b. Taro-wa [eki-de kinoo nai-te ${ }^{\text {prog }}$ iru $^{\text {pres }}$ otoko]-o ototoi

Taro-Top [station-at yesterday cry ${ }^{\text {prog }}$ be $^{\text {pres }}$ man] the day before yesterday

mise-de mi-ta ${ }^{\text {past }}$

store-at see past $^{\text {pas }}$

'The day before yesterday Taro saw at the store the man who was crying yesterday'

We will derive the observed distribution in a fully interpreted system. To do that, we need the following ingredients: the syntax and semantics of Tense, and a mechanism that licenses morphological tense. The differences observed will follow from the so-called SOTparameter and the Tense systems of the different languages.

\section{TENSE}

\subsection{Syntax of Tense}

Tense in subordinate constructions may be interpreted differently from matrix tense. The picture that has emerged over the last twenty years is the following: tense in complements is semantically vacuous or contains a vacuous centre. Tense in adjuncts is deictic or contains a variable bound by a higher tense. These claims are based on the following syntax of tense.

Tenses in natural language consist of two parts, the first obligatory and the second optional:

(a) a temporal centre or perspective point. The T-centre is either the deictic pronoun $\mathrm{n}$ ("now") denoting the speech time s*, or an anaphoric pronoun Tpro ("then") bound by some other tense, or the semantically empty pronoun TPRO, which has to be moved for type reasons thus creating a temporal $\lambda$-abstract.

(b) a (existentially quantified) temporal relation, which introduces a reference time with respect to the perspective point. Temporal relations such as PAST "there is a time before" and FUTURE "there is a time after" are called T-shifters.

Hence the structure of the Tense Phrase (TP) is this:

(6) Tenses as quantifiers with a pronominal centre 


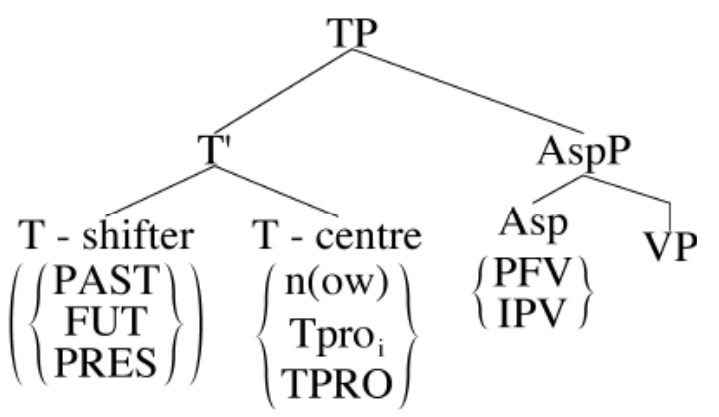

We follow common practice and assume an Aspect projection between the tense projection and the VP. We give some comments on the integration of Aspect in section 3.2, but for most of the purposes of the paper, Aspect can be ignored.

We classify semantic tenses according to their T-centre: n: deictic present, Tpro: anaphoric tense, TPRO: zero tense. For instance, PAST(n) is a deictic Past, i.e. there is a time before "now". PAST $\left(\operatorname{Tpro}_{\mathrm{i}}\right)$ is a relative anaphoric Past, i.e., there is a time before "then" (before a definite time). Finally, PAST(TPRO) is a relative zero Past, e.g., there is a time before the subjective time of the attitude holder.

The prefix " $T$ " reminds us that these pronouns stand for times. In terms of Chomsky's Binding Theory $\mathrm{n}$ is an R-expression, Tpro is a B-element, i.e. free in the smallest binding domain, whereas TPRO is the temporal version of the covert relative pronoun of (Heim and Kratzer, 1998), ch.8.5, pp. 226ff.. TPRO is moved for type reasons, leaving a co-indexed trace and having its binding index interpreted as a $\lambda$-operator. The notation TPRO is inspired by (von Fintel and Heim, 2000), who use W-PRO as a notation for the semantically empty pronoun for worlds, i.e. as a device that creates $\lambda$-abstracts over world variables.

Details aside, our quantificational approach to tense is used in (Ogihara, 1989), (Kamp and Reyle, 1993), (Heim, 1997), (Kusumoto, 1999), (Grønn and von Stechow, 2011, von Stechow, 2009) and many others. Another theory of tense, which has become popular since (Abusch, 1994, Heim, 1994a) and (von Stechow, 1995), is the referential approach.

\subsection{Semantics of Tense and $L F$}

We use an intensional $\lambda$-categorial language for the LF-representations. The logical types are e (individuals), i (time intervals), t (truth-values), s (worlds). Functional types are written as (ab) or simply ab. We first state the meanings of the components of the TP together with their morphological features, which will be explained below. 
T-centres
a. Deictic Present: $\llbracket n \rrbracket^{c}=\lambda w . s^{*} \quad$ feature: [i-pres] $\mathrm{s}^{*}$ is a time interval containing the speech time given by the context $\mathrm{c}$
b. $\quad\left[\operatorname{Tpro}_{\mathrm{i}} \rrbracket^{\mathrm{g}}=\mathrm{g}(\mathrm{i})\right.$
c. [ITPRO] undefined!

T-shifters
c. $\quad\left[\operatorname{PAST}_{(\mathrm{i},(\mathrm{it}, \mathrm{t}))} \rrbracket=\lambda \mathrm{w} \lambda \mathrm{t} \lambda \mathrm{P}_{\mathrm{it} \cdot} \cdot\left(\exists \mathrm{t}^{\prime}<\mathrm{t}\right) \mathrm{P}\left(\mathrm{t}^{\prime}\right)\right.$
feature: [i-past]
d. $\llbracket \mathrm{FUT}_{\text {Russian }} \rrbracket=\lambda w \lambda \mathrm{t} \lambda \mathrm{P}_{\mathrm{it} \cdot}\left(\exists \mathrm{t}^{\prime}>\mathrm{t}\right) \mathrm{P}\left(\mathrm{t}^{\prime}\right)$
feature: [i-fut]

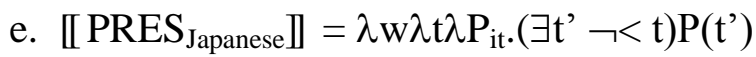
feature: [i-pres]

The meanings are intensions as in (Heim and Kratzer, 1998), ch.12. H\&K don't write the meanings as $\lambda$-abstracts over worlds; the local evaluation world is instead a parameter.

Consider the PF ("phonetic form") and LF for the simple sentence below:

$$
\begin{aligned}
& \text { Mary slept. } \\
& \text { [те [т PAST } \left.\left.\mathrm{n}] \text { TPRO } \lambda_{\mathrm{i}}\left[\mathrm{vP} \text { Mary [sleep } \mathrm{t}_{\mathrm{i}}\right]\right]\right] \\
& =\lambda \mathrm{w} .\left(\exists \mathrm{t}<\mathrm{s}^{*}\right) \text { Mary sleeps at } \mathrm{t}
\end{aligned}
$$

We see that the verb of the PF in (8) has morphological tense, whereas at the LF (9) the verb is tenseless. Assuming the following meaning for the verb,

$$
\llbracket \text { sleep }_{i(e t)} \rrbracket=\lambda w \lambda t \lambda x \cdot x \text { sleeps in } w \text { at time } t \text {, }
$$

(9) has a straightforward compositional interpretation, which is indicated below the LF. We will represent verbs with morphological tense as a composition of verb + tense feature, e.g., the PF-version of slept is represented as sleep+past, whereas the LF-version of slept is sleep. We will comment on the deleted TPRO in a moment.

Let us call the operators under T' semantic tenses, i.e., the semantic tenses are Tshifter(n), T-shifter(Tpro ${ }_{i}$ ), T-shifter(TPRO), n, Tpro ${ }_{i}$, TPRO, where T-shifter stands for PAST, FUT Rus $_{1}$, PRES $_{\text {Jap. }}$. The features [past], [fut] and [pres] are called morphological tenses. Given this account, it follows that the (covert) semantic tenses are semantically interpreted, while the (overt) morphological tenses are not semantically interpreted. At PF it is the other way round; the semantic tenses are not interpreted (therefore covert) but the morphological tenses are interpreted (and therefore overt). The function of a particular tense feature is to point at the presence of a particular semantic tense. It follows that there must be a relation between semantic tense and morphological tense, namely the licensing relation. 
Readers unfamiliar with the semantic/morphological tense distinction are likely to be confused. So let us illustrate the terminology again by considering examples from English and Russian expressing a future event time:

$$
\begin{array}{ll}
\text { John will leave. } & \text { (semantic tense is Present) } \\
\text { John woll } & \\
\text { Masha } \text { ledet. } & \text { (semantic tense is Future) } \\
\text { Masha leave } &
\end{array}
$$

Ignoring aspect, these sentences are truth-conditionally equivalent, but their LFs are different, namely (13) and (14), respectively.

$$
\mathrm{n} \text { TPRO } \lambda_{1} \text { woll }\left(\mathrm{t}_{1}\right) \text { TPRQ } \lambda_{2} \text { John leave }\left(\mathrm{t}_{2}\right)
$$

woll represents the stem of the temporal auxiliary will, as is standard in the literature; cf. (Abusch, 1994). This LF shows that the semantic tense of (11) is Present.

$$
\mathrm{n} \text { TPRO } \lambda_{1} \mathrm{FUT}_{\mathrm{Rus}}\left(\mathrm{t}_{1}\right) \text { TPRO } \lambda_{2} \operatorname{Masha} \text { leave }\left(\mathrm{t}_{2}\right)
$$

As the LF for the Russian sentence reveals, the semantic tense of the sentence is Future. Analogous facts hold for German, where the simple past and the present perfect are synonymous, again an effect of the compositional semantics of the auxiliary and n:

$$
\text { Elin war krank. (Elin was sick) }
$$

(semantic tense is Past)

$$
\text { Elin ist krank gewesen. (Elin has been sick) (semantic tense is Present) }
$$

Here is the meaning of some temporal auxiliaries, which are special temporal quantifiers because they have the format of generalized quantifiers over times.

$$
\text { Temporal Auxiliaries }
$$

a. be

$$
\lambda w \lambda t \lambda P_{i t} \cdot P(t)
$$

b. woll (Eng.), bud (Rus.)

feature: [i-infinitive]

$$
\lambda w \lambda t \lambda P_{i t} \cdot\left(\exists t^{\prime}>t\right) P\left(t^{\prime}\right)
$$

c. hab/sei (Ger.)

feature: [i-past participle]

$$
\lambda w \lambda t \lambda P_{i t} \cdot\left(\exists t^{\prime}<t\right) P\left(t^{\prime}\right)
$$

The logical type (i,(it,t)) is taken from (Heim, 1997), i.e. we have the local evaluation time as the first argument. Other authors have the local evaluation time as the last argument, e.g. (Kratzer, 1998) and (Kusumoto, 2005). 
Note that woll/bud have the same meaning as the FUT tense in Russian. Similarly, German hab has the same meaning as PAST.

Under the present account every morphological variant of a verb has a timeless interpretation, i.e. every verb form of a paradigm means the same. But finite verb forms have different temporal features and the latter point to covert semantic tenses, which are responsible for the different meanings, as shown below:

(18) Some morphological forms with pronunciation rules (PF spell-out):

$$
\begin{aligned}
& \text { sleep }^{3 \mathrm{rd}, \text { sg,pres }}=\text { sleeps } \\
& \text { sleep }^{3 \mathrm{rd}, \text { sg,past }}=\text { slept } \\
& \text { sleep }^{\text {past,part }}=\text { slept } \\
& \text { sleep }^{\text {inf }}=\text { sleep }
\end{aligned}
$$

Interpreted LF for all of these:

$\llbracket \operatorname{sleep}_{\mathrm{i}(\mathrm{et})} \rrbracket=\lambda \mathrm{w} \lambda \mathrm{t} \lambda \mathrm{x} . \mathrm{x}$ sleeps in $\mathrm{w}$ at $\mathrm{t}$.

Next we illustrate the rules of construal for the LF in (9). We assume a grammar in the style of Chomsky's GB-theory, i.e. a T-model: we generate a syntactic tree that branches at a certain point (Spell-Out/SO) into Phonetic Form and Logical Form. The derivation of the LF in (9) is the following, where morphological features are ignored:

$$
\begin{aligned}
& \text { SO: [тр [т PAST n] [vр Mary [sleep TPRO]]] } \\
& \text { TPRO-movement (with subsequent TPRO deletion) } \\
& \text { LF: [те [т PAST n] TPRO } \left.\lambda_{1}\left[\text { vр Mary [sleep } \mathrm{t}_{1}\right]\right]
\end{aligned}
$$

The temporal argument of the verb is a semantically vacuous TPRO. TPRO has to be moved for type reasons creating the temporal variable $t_{1}$. The binding index 1 of TPRO is interpreted as $\lambda_{1}$. At LF, TPRO is deleted by Chomsky's principle of Full Interpretation. Thus we arrive at the fully transparent LF in (9). The idea of creating $\lambda$-abstracts by PRO-movement was introduced in (Heim and Kratzer, 1998). For the analysis of the relative pronoun, this method has gained popularity recently. An alternative is to allow free $\lambda$-insertion, whenever this is needed for the semantic composition; vide, e.g. (Kratzer, 1998), (Kusumoto, 1999) and many others. In what follows, we will mostly write the LFs without the deleted TPRO, i.e., instead of TPRO $\lambda_{\mathrm{i}}$ we will simply write $\lambda_{\mathrm{i}}$. 


\subsection{Feature Transmission}

The LFs show that a semantic tense is distant from the verb it modifies. But every semantic tense is connected with at least one verb via a binding chain. The relevant binding notion is that in (Heim and Kratzer, 1998), chap. 5:

A DP $\alpha$ binds a DP $\beta$ iff $\beta$ and the trace of $\alpha$ are bound by the same variable binder ( $\lambda$-operator).

The feature theory defended by Irene Heim (most recently in (Heim, 2005)), p. 26, is this:

(21) Feature Transmission under Variable binding

In the derivation of PF all features of a DP must be copied onto all variables that it binds.

One of the sentences that motivated Heim's account is the following:

(22) Only I did my homework.

$=\mathrm{c}_{\mathrm{S}}$ did $\mathrm{c}_{\mathrm{S}}$ 's homework \& $\neg\left(\exists \mathrm{x}_{1}, \mathrm{x}_{1} \neq \mathrm{c}_{\mathrm{S}}\right) \mathrm{x}_{1}$ did $\mathrm{x}_{1}$ 's homework

$\mathrm{c}_{\mathrm{S}}$ (the speaker of $\mathrm{c}$ ) is the interpretation of $\mathbf{I}$, and $\mathrm{x}_{1}$ 's is the translation of $\mathbf{m y}$. We could

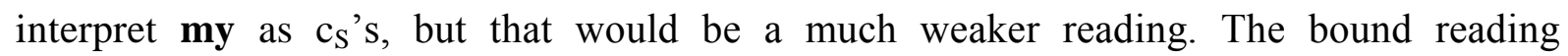
represented under (22) interprets my simply as a bound variable. Thus the feature $\left[1^{\text {st }}\right.$ person] is not interpreted there. (Heim, 2002) gives a derivation that shows that the feature $\left[1^{\mathrm{st}}\right]$ of $\mathbf{I}$ in only $\mathbf{I}$ is transmitted under binding to the variable contained in the possessive my.

Assuming that the host of the tense feature that determines the pronunciation is the time variable of the verb, it is a natural move to conceive of tense licensing as Heim's feature transmission under semantic binding. A semantic tense transmits its feature under binding to the temporal variable it binds. The relevant LF-configuration of the sentence in (8) is the following:

$$
\begin{aligned}
& \text { Mary slept }
\end{aligned}
$$

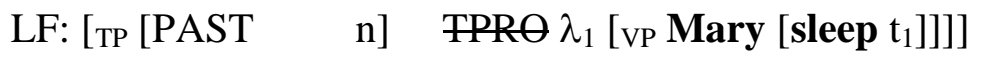

$$
\begin{aligned}
& \text { i-past i-pres u-past } \\
& \text { | } \\
& =\lambda \mathrm{w} \cdot\left(\exists \mathrm{t}<\mathrm{s}^{*}\right) \text { Mary sleeps in } \mathrm{w} \text { at } \mathrm{t}
\end{aligned}
$$

The prefixes i- ("interpretable") and u- ("uninterpretable") are used in recent Generative Grammar and also in our own papers. The i-prefix simply marks the (lexical) origin of the 
feature. At PF, i-features are deleted and u-features are pronounced. At LF, both i-features and u-features are deleted (cf. (von Stechow, 2003)), or these features are only present on the PF-branch (cf. (Heim, 2005). Our account is compatible with both views.

Here is a note on Aspect. (Kusumoto, 1999, Kusumoto, 2005) identifies the morphological tense of an inflected verb with the temporal variable of the verb, writing past $\mathbf{p}_{\mathbf{i}}$ for our [ $\mathrm{t}_{\mathrm{i}} \mathrm{u}$-past]. This identification is problematic for the following reason. In languages such as Russian, the verb is not only marked for tense but also for aspect. The generally accepted picture is that there is an aspect projection between the tense projection and the VP, and the aspect feature comes from the semantic aspect heading the aspect phrase. Consider a possible translation of (8) into Russian:

$$
\begin{aligned}
& \text { Masha pospala ('Masha slept for a while') } \\
& \text { Masha po-sleep }{ }^{\text {pfv,past }} \quad[\mathrm{pfv}=\text { perfective }]
\end{aligned}
$$

The standard meaning for perfective aspect is as follows, where $\mathrm{v}$ is the type of events and $\tau(\mathrm{e})$ is the running time of the event e.

$$
\left[\left[P^{\prime} V_{i(v t, t)} \rrbracket=\lambda w \lambda t \lambda P .(\exists e)[\tau(e) \subset t \& P(e)] \quad \text { feature: }[i-p f v]\right.\right.
$$

The meaning of the verb po-sleep ("po" is a Russian prefix) is something like this:

$$
\left[\text { po-sleep }{ }_{v(\mathrm{et})} \rrbracket=\lambda \mathrm{w} \lambda \mathrm{e} \lambda \mathrm{x} \text {.e is a complete nap done by } \mathrm{x} \text { in } \mathrm{w}\right.
$$

A structure with feature transmission for the sentence in (24) is therefore the following:

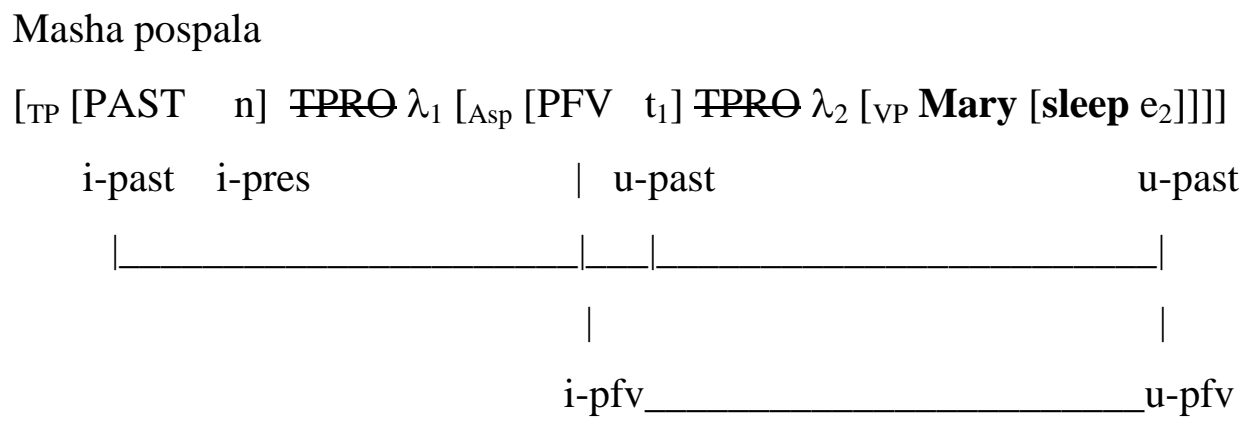

$\lambda \mathrm{w} .\left(\exists \mathrm{t}<\mathrm{s}^{*}\right)(\exists \mathrm{e}$ with $\tau(\mathrm{e}) \subset \mathrm{t})$ e is a complete nap by Masha in $\mathrm{w}$

Here the tense feature [past] is first transmitted to the variable $t_{1}$ of PFV. The feature [i-pfv] of the operator is not in conflict with [u-past]. The latter is therefore transmitted to the event variable $e_{2}$ of the verb. The feature [i-pfv] is transmitted to the same variable. Thus the event variable of sleep carries both a tense and aspect feature, determining the pronunciation as pospala. This is not possible in Kusumoto's account, which therefore requires some further assumptions. We will assume that a variable may carry several 
features as long as there is no conflict.

The last example illustrates a crucial assumption of our theory. In logical terms, an intervening $\lambda$-operator breaks a binding chain. There is no semantic binding relation between [PAST $n$ ] and the variable $e_{2}$. We assume that features are further transmitted by intervening operators - here the Aspect operator PFV - as long as there is no feature conflict. On the other hand, the feature [i-pres] of the $\mathrm{n}$ that is the argument of PAST is not transmitted by PAST because PAST has the conflicting feature [i-past].

\section{Tense in Relative Clauses}

\subsection{Methodology}

In extensional contexts, when the relative clause $(\mathrm{RC})$ is not in the scope of a modal or attitude, we expect that the tense of the $\mathrm{RC}$ is independent of a higher tense, i.e. deictic. If, however, we encounter a tense mismatch, that is, a tense with an unexpected denotation, binding must be involved. Given that local binding by an intensional operator is not possible for reasons of the configuration, the tense in the $\mathrm{RC}$ must have a bound $\mathrm{Tpro}_{\mathrm{i}}$ as its $\mathrm{T}$-centre. This Tpro $_{i}$ will inherit the temporal features from a higher tense and determine the temporal morphology of the main verb in the RC.

\subsection{English}

Relative clauses are formed by wh-movement of the relative pronoun. We represent the relative pronoun as $\mathrm{WH}$ and identify it with PRO. Since $\mathrm{WH}$ is semantically void, it is moved for type reasons and creates a $\lambda$-abstract. Here is the analysis of (1a):

$$
\begin{aligned}
& \left.\operatorname{PAST}(\mathrm{n}) \lambda_{1} \text { John meet }\left(\mathrm{t}_{1}\right) \text { a man [RC WH} \mathrm{WH}_{2} \operatorname{PAST}(\mathrm{n}) \lambda_{3} \operatorname{be}\left(\mathrm{t}_{3}\right) \lambda_{4} \mathrm{x}_{2} \operatorname{cry}\left(\mathrm{t}_{4}\right)\right] \\
& \text { i-past_u-past } \quad \text { i-past_u-past } \\
& =\left(\exists \mathrm{t}_{1}<\mathrm{s}^{*}\right)(\exists \mathrm{x})\left[\operatorname{man}(\mathrm{x}) \&\left(\exists \mathrm{t}_{3}<\mathrm{s}^{*}\right)\left[\operatorname{cry}\left(\mathrm{x}, \mathrm{t}_{3}\right)\right] \& \operatorname{meet}\left(\mathrm{John}, \mathrm{x}, \mathrm{t}_{1}\right)\right]
\end{aligned}
$$

The Tense in the RC is independent from the matrix Tense. Both morphological tenses are licensed by a local Past. We will speak of local tense licensing in such cases. The LF neglects Quantifier Raising (QR) of the object. The representation omits the world variable in the meta-language, because the construction is extensional. Henceforth, we will only use worlds in intensional constructions.

The more interesting cases are the Ogihara/Abusch examples. Here is the analysis of the bound reading of $(1 \mathrm{c})$ : 


$$
\begin{aligned}
& \mathrm{n} \lambda_{2} \text { woll }\left(\mathrm{t}_{2}\right) \lambda_{3} \text { John buy }\left(\mathrm{t}_{3}\right) \text { a fish } \mathrm{WH}_{4} \mathrm{Tpro}_{3} \lambda_{5} \text { is }\left(\mathrm{t}_{5}\right) \lambda_{6} \mathrm{X}_{4} \text { alive }\left(\mathrm{t}_{6}\right) \\
& \text { i-pres_u-pres__u-pres___u-pres__u-pres } \\
& =\left(\exists \mathrm{t}_{2}>\mathrm{s} *\right)(\exists \mathrm{x})\left[\mathrm{fish}(\mathrm{x}) \& \operatorname{alive}\left(\mathrm{x}, \mathrm{t}_{2}\right) \& \operatorname{buy}\left(\mathrm{John}, \mathrm{x}, \mathrm{t}_{2}\right)\right]
\end{aligned}
$$

In this construction, the verb in the relative inherits its present feature from the matrix $\mathrm{n}$ via a binding chain that goes across the temporal auxiliary woll. This is an example of long distance tense licensing. Long distance licensing is possible in Sequence of Tense (SOT) languages such as English, but not in non-SOT languages like Russian or Japanese. The following parameter distinguishes between the two classes of languages:

The SOT-parameter (Grønn and von Stechow, 2010), slightly revised

A language $L$ is an SOT language if and only if

(i) temporal quantifiers of $\mathrm{L}$ without temporal i-features transmit temporal features;

(ii) intensional temporal quantifiers do not license present tense morphology.

Extensional temporal quantifiers have the type i(it,a), the intensional ones are of type $\mathrm{i}((\mathrm{s}(\mathrm{it})), \mathrm{a})$, where a is a type ending in t. Applied to the last example the parameter tells us that woll doesn't block feature transmission in English. For alternative formulations of the SOT-rule, see section 6.4.

Another point should be mentioned: the verb buy inherits the feature [u-pres], but it isn't pronounced on the verb, since buy also inherits the status feature [u-inf] which determines the pronunciation. The term status feature is due to (Bech, 1955/57). For status features we have to postulate that they are only transmitted to the first variable bound.

The sentence in (1d) is analyzed with a bound Tpro ${ }_{i}$ in the RC as well, but we have a local Past, which is responsible for the tense licensing:

$$
\begin{gathered}
\mathrm{n} \lambda_{1} \operatorname{woll}\left(\mathrm{t}_{1}\right) \lambda_{2} \operatorname{John} \operatorname{meet}\left(\mathrm{t}_{2}\right) \text { a man } \mathrm{WH}_{3} \operatorname{PAST}\left(\operatorname{Tpro}_{2}\right) \lambda_{4} \mathrm{x}_{3} \operatorname{lose}\left(\mathrm{t}_{4}\right) \mathrm{x}_{3}{ }^{\prime} \text { s money } \\
\left(\exists \mathrm{t}_{2}>\mathrm{s}^{*}\right)(\exists \mathrm{x})\left[\operatorname{man}(\mathrm{x}) \&\left(\exists \mathrm{t}_{4}<\mathrm{t}_{2}\right)\left[\operatorname{lose}\left(\mathrm{x}, \mathrm{t}_{4}, \mathrm{x} \text { 's money }\right)\right] \& \operatorname{meet}\left(\operatorname{John}, \mathrm{x}, \mathrm{t}_{2}\right)\right]
\end{gathered}
$$

We have local tense licensing in the $\mathrm{RC}$, but the tense is bound by woll and therefore not deictic. There is a deictic construal as well. In that case we have $\mathrm{n}$ as the T-centre in the RC, and the time of the losing is before the speech time.

When an Abusch/Ogihara sentence is embedded under an attitude, the tense in the RC may be licensed by the matrix Tense across the verb of attitude. Consider the following example by Ogihara: 

Yesterday John said that in ten days he would buy a fish that was alive (then).

Verbs of attitude like said or believed are intensional temporal quantifiers; cf. (Kratzer, 1998, von Stechow, 1995), among others. In our theory they transmit their temporal features under binding. Hence (31) has the following analysis:

$$
\begin{aligned}
& \text { n } \lambda_{1} \operatorname{PAST}\left(\mathrm{t}_{1}\right) \lambda_{2} \mathbf{J} . \operatorname{say}\left(\mathrm{t}_{2}\right) \operatorname{TPRO} \lambda_{3} \operatorname{woll}\left(\mathrm{t}_{3}\right) \lambda_{4} \text { he buy }\left(\mathrm{t}_{4}\right) \\
& \text { i-past__u-past____ u-past___ u-past } \\
& \text { a fish } \mathrm{WH}_{5} \mathrm{Tpro}_{4} \lambda_{6} \text { be }\left(\mathrm{t}_{6}\right) \lambda_{7} \mathrm{x}_{5} \text { alive }\left(\mathrm{t}_{7}\right) \\
& \text { u-past__u-past } \\
& =\lambda \mathrm{w} .\left(\exists \mathrm{t}_{2}<\mathrm{s}^{*}\right)\left[\operatorname { s a y } _ { \mathrm { w } } \left(\mathrm{John}, \lambda \mathrm{w}^{\prime} \lambda \mathrm{t}_{3} \cdot\left(\exists \mathrm{t}_{4}>\mathrm{t}_{3}\right)(\exists \mathrm{x})\left[\mathrm{fish}_{\mathrm{w}},(\mathrm{x}) \& \operatorname{alive}_{\mathrm{w}},\left(\mathrm{x}, \mathrm{t}_{4}\right) \&\right.\right.\right. \\
& \text { buy } \left.\left.\left._{\mathrm{w}},\left(\text { he, } \mathrm{x}, \mathrm{t}_{4}\right)\right], \mathrm{t}_{2}\right)\right]
\end{aligned}
$$

There is a binding chain from PAST down to the embedded be. be is not interpreted before the speech time but (10 days) after the "subjective now" of John, i.e., 9 days after s* if John is right about the time.

Here is a side remark concerning the distribution of the temporal auxiliary would: it cannot be embedded under a matrix Past, cf. (Abusch, 1993):

*Yesterday Mary would visit me today.

Intended reading: $\left(\exists \mathrm{t}<\mathrm{s}^{*}\right)\left[\mathrm{t} \subseteq\right.$ yesterday \& $\left(\exists \mathrm{t}^{\prime}>\mathrm{t}\right)\left[\mathrm{t}^{\prime} \subseteq\right.$ today \& Mary visits me at t']]

In order to get the distribution right we have to stipulate the following binding condition for would.

$$
\text { woll }^{\text {past }} \text { must be (locally) bound by Tpro }{ }_{i} \text { or TPRO. }
$$

In (31) this condition is met, while in the LF for (33) it is violated.

Finally, we note that a deictic Tense in a RC has to be converted into an anaphoric bound tense when it occurs in an intensional context. Take for instance (1a) and embed it under John said:

PAST(n) John said that he met a man who was crying in sorrow. i-past u-past u-past u-past

Here, the Tense of the embedded RC must be $\mathrm{Tpro}_{\mathrm{i}}$ that inherits the feature [u-past] from the matrix Past via an extended binding chain.

Summary: In RClwoll configurations, the Tense in the RC is bound, i.e., the T-centre 
is Tpro $_{i}$. In this case we have long distance tense licensing. The possibility of long distance dependencies of this kind is predicted by the SOT-parameter.

\subsection{Russian}

The standard account for Russian RCs is that their tense is always independent in extensional contexts (see, e.g. (Kusumoto, 1999)). We noted in section 2 that we find a relative Future under Past, so the claim is not entirely true.

The deictic cases are analyzed exactly as the deictic configurations in English; see, e.g., (28).

An interesting prediction follows for the Preslwoll configurations. The auxiliary budet means the same as English will. Since Russian is a non-SOT language, the SOT-parameter implies that budet does not transmit its temporal feature; nor does it license an embedded present, being an extensional quantifier. It follows that Preslbudet cannot have a simultaneous interpretation and therefore must be deictic.

(36) Olga budet zamuzhem za vrachom, kotoryj zhivet v Murmanske. (only deictic)

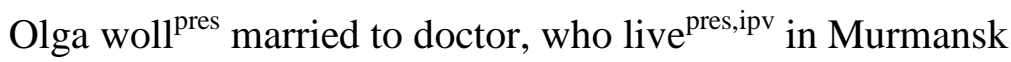

'Olga will be married to a doctor who lives in Murmansk.'

So the main tense in the RC must either be $\mathrm{n}$ or $\mathrm{Tpro}_{\mathrm{i}}$ bound by matrix $\mathrm{n}$. In both cases the interpretation is the speech time $\mathrm{s}^{*}$. Note that the Pres $\backslash$ budet configurations motivate our assumption that Russian does not have a relative Present. Otherwise, the embedded Present could have been shifted. In attitudes, an embedded present is licensed by the attitude verb (clause (ii) of the SOT- parameter).

Below we repeat the FuturelPast configuration with a shifted, non-deictic interpretation:

$$
\begin{aligned}
& \text { V universitete devushka poznakomilas’ s Billom Klintonom, kotoryj } \\
& \text { at university girl } \text { know }^{\text {past,pfv }} \text { with Bill Clinton who } \\
& \text { vposledstvii stanet ee muzhem. (Google) } \\
& \text { later become } \mathrm{fut}^{\text {futp }} \quad \text { her husband }
\end{aligned}
$$

In Russian we find the synthetic (inflectional) future stanet where we have the analytical form would become in English. Both forms clearly express a relative future because the 
marriage was before the speech time. For convenience we indicate the LF for the Russian sentence using English words:

$$
\begin{aligned}
& \text { n } \lambda_{0} \operatorname{PAST}\left(\mathrm{t}_{0}\right) \lambda_{1} \text { girl get-to-know }\left(\mathrm{t}_{1}\right) \text { B.C. } \\
& \text { i-past__u-past } \\
& \mathrm{WH}_{2} \quad \mathrm{FUT}_{\mathrm{Rus}}\left(\mathrm{Tpro}_{1}\right) \lambda_{3} \mathrm{x}_{2} \text { become-fut }\left(\mathrm{t}_{3}\right) \text { her husband } \\
& \text { i-fut } \\
& \text { u-fut } \\
& =\left(\exists \mathrm{t}_{1}<\mathrm{s}^{*}\right) \text { [girl get-to-know }\left(\mathrm{t}_{1}\right) \text { B.C. } \&\left(\exists \mathrm{t}_{3}>\mathrm{t}_{1}\right) \text { [B.C. become }\left(\mathrm{t}_{3}\right) \text { her husband] }
\end{aligned}
$$

A relative Future under Past is possible in Russian because FUT $_{\text {Rus }}$ induces its own feature [i-fut], which licenses the future verb in the RC. Note that the time argument of FUT $_{\text {Rus }}$ has to be a Tpro ${ }_{i}$ bound by the matrix Past in this construction. This is a counterexample to the claim that tenses in Russian RCs are always deictic.

Summary: In most constructions the RC-tense is deictic. The SOT-parameter predicts that Presentlbudet is deictic as well. We can, however, have a shifted interpretation of Future \Past; here we must assume a bound $\mathrm{Tpro}_{\mathrm{i}}$. In each case, tense licensing in Russian RCs is local.

\subsection{Japanese}

Finally, consider relative clauses in the non-SOT language Japanese. In PastlPast configurations the embedded Past can be analyzed as deictic, like in Russian and English. The interesting data are the Pres\Past configurations, where the embedded Pres can be simultaneous with the time introduced by the matrix Past as in (5a) or forward shifted with respect to the past time as in (5b).

Recall that Japanese has a relative present PRES Jap, which is a non-Past, as it is generally assumed in school grammars; see e.g. (Banno et al., 1990), p. 58 ff.. The two readings (deictic and simultaneous) of the sentence in (5a) are then analyzed as follows, where our LF respects the Japanese word order:

$$
\begin{aligned}
& \text { n } \lambda_{1} \operatorname{PAST}\left(\mathrm{t}_{1}\right) \lambda_{2} \operatorname{Taro}\left[{ }_{\mathrm{NP}}\left[\mathrm{RC} \mathrm{WH}_{3} \operatorname{PRES}_{\mathrm{Jap}}\left(\mathrm{Tpro}_{1 / 2}\right) \lambda_{4} \mathrm{x}_{3} \operatorname{cry}\left(\mathrm{t}_{4}\right)\right] \operatorname{man}\right] \operatorname{see}\left(\mathrm{t}_{2}\right) \\
& \text { i-past } \\
& \text { i-pres } \\
& \text { u-pres } \\
& \text { u-past }
\end{aligned}
$$

$\left(\exists \mathrm{t}_{2}<\mathrm{s}^{*}\right)$ Taro sees at $\mathrm{t}_{2} \mathrm{a} /$ the man who is crying at $\mathrm{s} * / \mathrm{t}_{2}$

If $\mathrm{Tpro}_{1}$ is bound by $\mathrm{n}$, we have the deictic reading. Tpro 2 bound by PAST gives us the shifted, simultaneous reading. The forward shifted reading in $(5 \mathrm{~b})$ is analyzed alike; since 
PRES $_{\text {Jap }}$ is a non-Past, this Tense is neutral with respect to simultaneity or forward shift.

Summary: The crucial point for understanding Tense in Japanese RCs is that Japanese has a relative Present; this makes Japanese different from Russian. As always in non-SOT languages, tense licensing is local in Japanese.

\section{INTERIM CONCLUSION}

1. In SOT languages such as English, the Tense in the RC is bound in RClwollconfigurations, i.e., we find a Tpro ${ }_{i}$ bound by woll. The licensing of the morphological tense in the RC is non-local in these cases. In most other constructions, the RC-Tense is deictic and tense licensing is local.

2. In Russian, a non-SOT language, the RC-Tense is bound in FUT Rus $I P A S T$ configurations. In other configurations, the RC-Tense is deictic. Tense licensing is local.

3. In Japanese, another non-SOT language, the RC-Tense can be bound in PRES $_{\text {Jap }} \backslash P A S T$ configurations. In other configurations, the RC-Tense is deictic. Tense licensing is local.

Note that Russian and Japanese are almost parallel: we find FUT $_{\text {Rus }}$ in Russian precisely at the place where we find PRES ${ }_{\text {Jap }}$ in Japanese.

\section{COMMENTS ON THE LITERATURE}

\subsection{Tense}

An alternative theory of tense is the referential approach (Abusch, 1994, Heim, 1994a) and (von Stechow, 1995). In this account, tenses are features that restrict the denotation of temporal variables.

(40) Tenses as pronouns with restrictors

a. Present: $\operatorname{pres}\left(\mathrm{t}_{\mathrm{i}}\right)$ with $\llbracket$ pres $\rrbracket=\lambda \mathrm{t}: \mathrm{t}=\mathrm{s} * \mathrm{t}$

( $\mathrm{s}^{*}$ is the speech time, the condition between ":" and "." is a presupposition; other restrictions have been proposed, for instance overlap, inclusion, non-past)

b. Past: $\operatorname{past}\left(\mathrm{t}_{\mathrm{i}}\right)$ with $\llbracket$ past $\rrbracket=\lambda \mathrm{t}$ : $\mathrm{t}$ before $\mathrm{s} * \mathrm{t}$

c. Zero tense: TPRO

A different kind of referential approach is proposed in (Kratzer, 1998). The semantic tenses present and past are deictic pronouns of type i, i.e. they denote a contextually given present 
time (present is our $n$ ) and a past time, respectively. Kratzer's zero tense $\varnothing_{i}$ is a time variable without features that is interpreted by the variable assignment $\mathrm{g}$ and carries no presuppositions. Kratzer's theory does not distinguish between our Tpro ${ }_{i}$ and TPRO.

Both the quantificational approach to tense in this paper and the alternative referential approaches have their weaknesses. There is no way of treating temporal anaphora in the quantificational approach.

John came home at 12. Mary was asleep (then).

The referential approach can have the same temporal variable (or the same deictic tense) in both sentences. A drawback of the referential approach is that it cannot account for backwards shifting in embedded contexts, e.g., in complement clauses:

(42) John said that Mary left.

Recall that a similar backward shifting reading is possible for tense in RC; cf. (1d). (Kratzer, 1998) assumes for such examples that the past tense is ambiguous between a referential tense and a quantificational relative past, which she calls Perfect Aspect. In Russian, an embedded synthetic future can shift the event time as well; cf. (4). Advocates of a referential theory would have to say that the Russian future is ambiguous between a referential tense and an Aspect, say Prospective. The quantificational approach needs no such ambiguities.

We believe that a theory of tense that is able to overcome the disadvantages of the two approaches mentioned will be a dynamic one, but we cannot discuss this here.

\subsection{Covert Temporal Pronouns}

The decomposition of tenses into a relational part (T-shifter) and a local evaluation time (our T-centre) is found in (Heim, 1997) and (Kusumoto, 1999) among others, but they don't use our terminology. The deictic constant $\mathrm{n}$ for the deictic present is used in (Kamp and Reyle, 1993); these authors also introduce the term "perspective point" for the T-centre.

The pronominal nature of tenses is stressed for the first time in (Partee, 1973). The notation $\mathrm{Tpro}_{\mathrm{i}}$ is due to Irene Heim (p.c.). Our architecture is closely related to that in (Kusumoto, 1999): she uses a special variable $t_{i} *$ for our $n$, Tpro and TPRO. The difference comes from the binding conventions. A free $t_{i} *$ is our $n$, a locally $\lambda$-bound $t_{i} *$ is our moved TPRO. A $\mathrm{t}_{\mathrm{i}}{ }^{*}$ bound by something in a higher clause is our $\mathrm{Tpro}_{\mathrm{i}}$.

Every more recent approach to tense agrees on the treatment of tense in complements of attitude verbs: under attitudes tense doesn't have any denotation. We have zero tense 
TPRO or a relative tense with a TPRO centre.

$$
\begin{aligned}
& \text { At } 6 \text { o'clock John } \text { Past }_{1} \text { thought it } \mathrm{TPRO}_{2} \text { was } 5 \text { o'clock } \\
& \lambda \mathrm{w} .\left(\exists \mathrm{t}_{1}<\mathrm{s}^{*}\right) \mathrm{t}_{1} \text { at } 6 \& \text { John thinks } \mathrm{w}_{\mathrm{w}} \text { at } \mathrm{t}_{1}\left(\lambda \mathrm{w}^{\prime} \lambda_{2} \cdot \mathrm{t}_{2} \text { is }_{\mathrm{w}} \text {, at } 5\right)
\end{aligned}
$$

The embedded past is a zero tense, realized as a $\lambda$-operator; see (Abusch, 1994), (von Stechow, 1995), (Kratzer, 1998) among others.

The idea of identifying PRO with a semantically empty pronoun is found at many places in Orin Percus' work; for an application to the temporal domain, see (Katz and Percus, 2008). A systematic theory of PRO and PRO-movement is first outlined in (Heim and Kratzer, 1998: 8.5.2), where PRO is an empty relative pronoun in NPs.

\subsection{Feature transmission}

The theory of feature transmission under semantic binding originates with a couple of papers of Irene Heim, e.g. (Heim, 1994b), (Heim, 2002), (Heim, 2005).

(Kusumoto, 1999) uses a structural account of feature licensing: a morphological tense (her temporal variables pres $_{\mathbf{i}} /$ past $_{\mathbf{i}}$ ) has to be c-commanded by a semantic tense (i.e. PRESENT/PAST). Since binding involves c-command, our feature transmission under variable binding can be interpreted as licensing under c-command. The approaches amount to the same, when it comes to feature licensing. We prefer a theory that licenses temporal features via semantic binding because we think that the checking of temporal features should be done with the same mechanism that Heim assumes for the $\varphi$-features person, number and gender.

(Kratzer, 1998) argues that bound variables always come from the lexicon without features. Since the arguments of verbs are bound variables, there are no lexical entries for verbs with features, contra (von Stechow, 2003). Instead, Kratzer does feature transmission via syntactic binding, i.e. co-indexation under c-command. The reason is that $\lambda$-abstraction as done by verbs and other operators "break" the binding chain. So $\lambda$-abstraction applies after feature transmission. We don't know how Kratzer's theory would treat Present complements of attitudes in non-SOT languages such as Russian and Japanese. Another problem is that it is not clear what syntactic binding into attitudes means: since intervening $\lambda$-operators break the binding chain, no semantic connection between the licensing semantic tense and the "bound" variable obtains. This raises the problem of setting the criteria for a correct co-indexing. On 
the other hand, our account is compatible with Kratzer's view that bound variables are born without features.

\subsection{Tense in RCs and the SOT Rule}

The first elaborate theory of tense in RCs is due to (Ogihara, 1989). Ogihara assumes that English only has a deictic relative present, while Japanese has a relative present throughout (it becomes deictic when it is not in the scope of another Tense). Ogihara's main plot is that the differences between English and Japanese can be explained if we as sume that English RCs (unlike Japanese) may undergo the SOT rule.

$$
\text { The SOT rule (simplified) (Ogihara, 1996), p.134 }
$$

A tense may be deleted if locally commanded by an occurrence of the same tense.

Locally means that no different tense intervenes. Deletion means substitution by zero tense $\varnothing$, which is interpreted as identity. The rule applies optionally if the structural conditions are met:

John Past said he Past would buy a fish that Past be alive.

In Ogihara's theory, RCs that contain a deictic Past have to be scoped over the matrix Past, because the lower Past is always shifted.

Kusumoto argues against this scoping approach with the "later"-reading in examples like the following:

(46) Hillary married a man who later became the president.

The adverb later restricts the time introduced by the lower Past to the time after the marrying. The complex object DP must therefore be in the scope of the matrix Past. Given that an embedded Past is always a backwards shifter in Japanese, the interpretation becomes inconsistent. The time of the RC cannot be both later and before the marrying.

Note that our approach has no problem with the example. later means $\lambda t^{\lambda} t^{\prime} . t^{\prime}>t$. The analysis of (46) is therefore:

$$
\begin{aligned}
& \operatorname{PAST}(\mathrm{n}) \lambda_{1} \text { Hillary marry }\left(\mathrm{t}_{1}\right) \text { a man } \mathrm{WH}_{2} \operatorname{PAST}(\mathrm{n}) \lambda_{3}\left[\operatorname{later}\left(\mathrm{t}_{1}\right)\left(\mathrm{t}_{3}\right) \& \mathrm{x}_{2} \text { become }\left(\mathrm{t}_{3}\right)\right. \\
& \quad \text { the president }] \\
& =\left(\exists \mathrm{t}_{1}<\mathrm{s}^{*}\right)(\exists \mathrm{x})\left[\operatorname{man}(\mathrm{x}) \&\left(\exists \mathrm{t}_{3}<\mathrm{s}^{*}\right)\left[\operatorname{later}\left(\mathrm{t}_{1}\right)\left(\mathrm{t}_{3}\right) \& \operatorname{becomes}\left(\mathrm{x}, \mathrm{t}_{3}, \text { the president }\right)\right] \&\right. \\
& \left.\quad \text { marry }\left(\text { Hillary, } \mathrm{x}, \mathrm{t}_{1}\right)\right]
\end{aligned}
$$

(Kusumoto, 1999)'s own SOT rule is this: 
a. SOT languages: a pres $/$ past $_{i}$ is licensed if it is locally c-commanded by a semantic tense operator PRES/PAST; chap. 2, (29), p. 111.

b. Non-SOT languages: past must be c-commanded by PAST in the same clause; chap. 2, (174), p. 227.

It is interesting to note that clause (b) of the rule doesn't include PRES ${ }_{\mathrm{Jap}}$. The reason is that Kusumoto rejects the existence of the relative Present in Japanese. She treats Japanese RCs as tenseless and has a rather complicated mechanism for their interpretation. We cannot discuss her arguments here, which we didn't find convincing. In particular, we don't know how Kusumoto could treat Ogihara's example (5b), where we find forward shifting in a Pres\Past configuration.

The relation between the different formulations of the SOT rule is this: when Ogihara has tense deletion across clauses, Kusumoto has tense licensing across clauses. When Ogihara's deletion rule does not apply, there is local tense licensing in Kusumoto's approach.

In our approach, temporal quantifiers play the role of clause boundaries. In SOT languages, an intensional temporal quantifier transmits a temporal feature, which ultimately ends up as morphological tense. In non-SOT languages, temporal quantifiers don't transmit tense features. This corresponds to Kusumoto's locality condition for tense licensing in nonSOT languages and Ogihara's stipulation that the SOT-rule doesn't apply in non-SOT languages.

The three accounts of the SOT-rule have in common that the licensing Tense 'commands' the licensed tense, i.e., when we have tense deletion in Ogihara's system, we have licensing under c-command in Kusumoto's system and feature transmission in our system.

\section{LITERATURE}

Abusch, Dorit. 1993. Two Theories of Tense in Intensional Contexts. Paper presented at Proceedings of the 9th Amsterdam Colloquium.

Abusch, Dorit. 1994. Sequence of Tense Revisited: Two Semantic Accounts of Tense in Intensional Contexts. In Ellipsis, Tense and Questions, ed. Hans Kamp. Stuttgart: Dyana-2 Esprit Basic research Project 6852.

Banno, Eri, Ohno, Yutaka, and Sakane, Yako. 1990. An integrated course in Japanese: The Japanese Times.

Bech, Gunnar. 1955/57. Studien über das deutsche Verbum infinitum: Danske Videnskabernes Selskab: Historisk-filologiske meddelelser. København: Munksgaard.

Grønn, Atle, and von Stechow, Arnim. 2010. Complement Tense in Contrast: The SOT parameter in Russian and English. In Russian in Contrast. Grammar, eds. A. Grønn 
and I. Marijanovic, 109 - 154. Oslo: Universitetet i Oslo.

Grønn, Atle, and von Stechow, Arnim. 2011. Future vs. Present in Russian and English Adjunct Clauses. Scando-Slavica Tomus 57:2:245-267.

Heim, Irene. 1994a. Comments on Abusch's theory of tense: Manuscript, MIT.

Heim, Irene. 1994b. Puzzling reflexive pronouns in de se reports: Handout from Bielefeld conference.

Heim, Irene. 1997. Tense in compositional semantics: MIT lecture notes.

Heim, Irene, and Kratzer, Angelika. 1998. Semantics in Generative Grammar: Blackwell Textbooks in Linguistics. Oxford/Malden, MA: Blackwell.

Heim, Irene. 2002. Features of Pronouns in Semantic and Morphology. Ms.

Heim, Irene. 2005. Features on bound pronouns. Ms. Cambridge/Mass.

Kamp, Hans, and Reyle, Uwe. 1993. From Discourse to Logic. Dordrecht/London/Boston: Kluwer Academic Publisher.

Katz, Graham, and Percus, Orin. 2008. Building up Expectations. Ms., DGfS Tense Across Languages Workshop. http://univ-nantes.academia.edu/OrinPercus/Papers/.

Kondrashova, Natalia. 1992. Tense Movement and Islands in Russian. Ms. University of Wisconsin, Madison.

Kratzer, Angelika. 1998. More Structural Analogies Between Pronouns and Tenses. In SALT VIII, eds. D. Strolovitch and A. Lawson. Cambridge, Mass.: Ithaca: CLC-Publications.

Kusumoto, Kiyomi. 1999. Tense in embedded contexts, Department of Linguistics, University of Massachusetts at Amherst: Ph.D. dissertation.

Kusumoto, Kiyomi. 2005. On the quantification over times in natural language. Natural Language Semantics 13:317-357.

Ogihara, T. 1996. Tense, Attitudes, and Scope. Dordrecht: Kluwer.

Ogihara, Toshiyuki. 1989. Temporal Reference in English and Japanese: University of Texas at Austin.

Partee, Barbara. 1973. Some Structural Analogies between Tenses and Pronouns in English. Journal of Philosophy 70:601-609.

von Fintel, Kai, and Heim, Irene. 2000. Notes on Intensional Semantics. Ms. Cambridge, Mass.

von Stechow, Arnim. 1995. On the Proper Treatment of Tense. In SALT V, eds. Teresa Galloway and Mandy Simons, 25: Cornell University.

von Stechow, Arnim. 2003. Feature Deletion under Semantic Binding: Tense, Person, and Mood under Verbal Quantifiers. In NELS 33, eds. Makoto Kadowaki and Shigeto Kawahara, 397-403. Amherst Massuchusetts: GLSA.

von Stechow, Arnim. 2009. Tenses in Compositional Semantics. In The Expression of Time, eds. Wolfgang Klein and Ping Li, 129 - 168. Berlin/New York: Mouton de Gruyter. 